\title{
Traction induction motor
}

\author{
Jakub Bernatt ${ }^{1, *}$, Stanistaw Gawron ${ }^{1}$, Tadeusz Glinka ${ }^{1}$, and Artur Polak ${ }^{1}$ \\ ${ }^{1}$ Institute of Electrical Drives and Machines KOMEL, Rozdzienskiego Ave. 188, 40-203, Katowice, Poland
}

\begin{abstract}
The paper presents a traction induction motor with an innovative rotor winding design. The winding of the rotor is almost identical to the armature winding in the dc traction motors, with the exception of commutator. Winding is double layered. The bars are insulated. Along the iron core bars are secured with wedges and in the winding outhang with bandages. The bars of the bottom layer in the winding outhang part near the iron core are bent radially in the direction of the shaft axis. On the winding outhang of the bottom layer an inner bandage is applied. On the winding outhang of the top layer an outer bandage is applied. All the ends of the bottom and top layers bars, on both sides of the rotor's core, are connected together by ferrule. There is a ring placed on the shaft or on the coil support on one side of the rotor's core. It is best if this ring is made of copper. The ring is characterized by $\mathrm{mp}$ tongues, which are distributed evenly along its circumference ( $\mathrm{p}$ is number of winding pole pairs and $\mathrm{m}$ is number of rotor winding phases). Tongues are connected to equally uniformly placed ferrules. Bandages are made of carbon fibre or glass fibre tape.
\end{abstract}

\section{Rotor winding of induction traction motor}

Induction motors for electric drives of rail vehicles are equipped with squirrel-cage rotor winding. These motors are supplied from inverters and used for traction drives of rail vehicles such as tram cars, metro cars, electric multiple units (EMUs), electric railway locomotives and mine locomotives. Drives using induction motors are characterized by high power efficiency and good control properties in two zones of speed control: one, where load torque is constant and the other, where load power is constant. Motors rated up to $100 \mathrm{~kW}$ (tram motors) are fitted with cast aluminium rotor winding. Larger motors are equipped with rotor winding made up of copper bars short-circuited with end rings. We may recall here

LK-450 X6 motors driving EMUs EN 57. One of the drawbacks of bar-type rotor winding is its high failure rate. After several years of service, the junction between winding bars and end ring cracks. This kind of damage is due to fatigue. The motors built into bogies are coupled with the wheels of traction vehicle via mechanical gearbox. Vibrations of drive wheels and tolerances of toothed gear are transmitted to the winding end-rings. This causes fatigue cracking of junctions between bars and end-rings. The authors of this paper became acquainted with the problem of end-ring breaking off during service tests run on railway vehicles under normal running conditions.
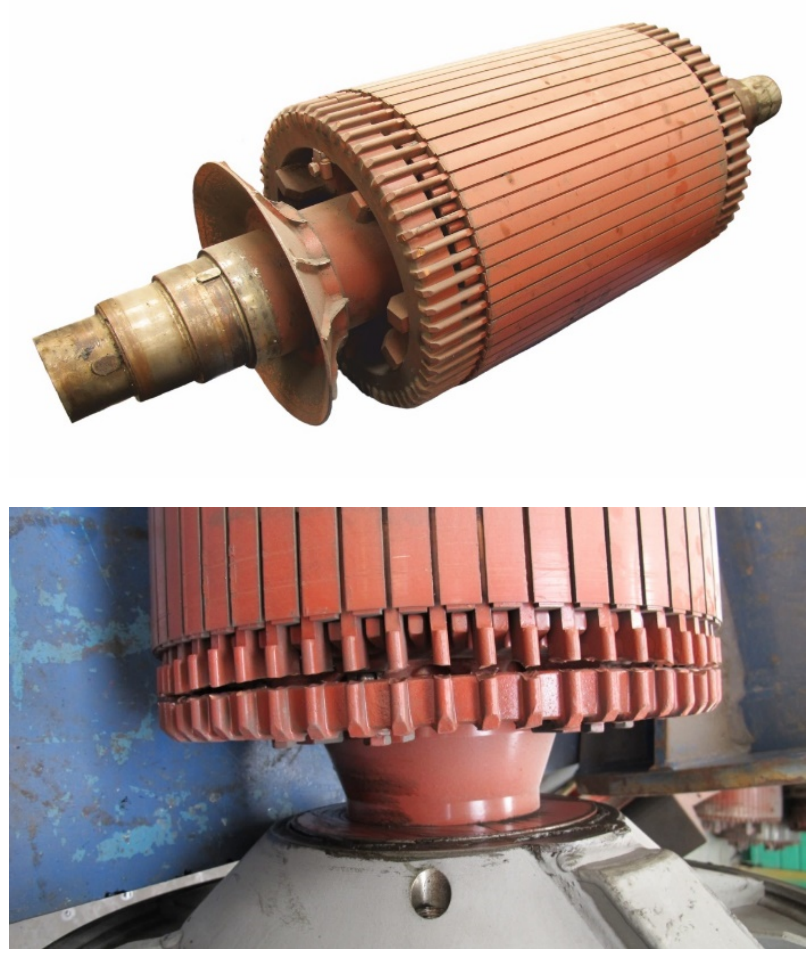

Fig. 1. Rotors of LK-450 X6 motor: brand-new one (upper photo) and with broken junctions between bars and end-ring (lower photo).

\footnotetext{
* Corresponding author: jakub.bernatt@komel.katowice.pl
} 
This problem is described in the literature of the subject, such as publication [2]. The old drive systems of rail vehicles used dc motors, which are characterized by much lower efficiency and high failure rate of commutators and brush holders. However, damages caused by ripping of bandages from coil outhangs were rare. Innovative design of rotor winding of induction motor is presented in the paper as well. The winding is manufactured in a manner similar to that of armature winding in dc traction motors, excepting the commutator and brush holding apparatus.

\section{Operating conditions of induction traction motors}

In this section we present results of investigating operating conditions of asynchronous LK450X6 traction motors, installed in EMU type EN57 AKM No. 1582. Tests were run in 2014. The ratings of induction LK-450 X6 motors are as shown in Table 1.

Table 1. The ratings of induction LK-450 X6.

\begin{tabular}{|c|c|}
\hline Power continuous rating/one-hour rating & $250 / 300 \mathrm{~kW}$ \\
\hline Rated voltage at $50 \mathrm{~Hz}$ frequency & $2340 \mathrm{~V}$ \\
\hline Rated/maximum frequency & $50 / 120 \mathrm{~Hz}$ \\
\hline Rated/maximum current & $78 / 160 \mathrm{~A}$ \\
\hline Rated/maximum rotational speed & $987 / 2400 \mathrm{rpm}$ \\
\hline Rated/maximum torque at $50 \mathrm{~Hz}$ & $2419 / 4400 \mathrm{~N} \cdot \mathrm{m}$ \\
\hline frequency & $6600 \mathrm{~N} \cdot \mathrm{m}$ \\
\hline Break-down torque at $50 \mathrm{~Hz}$ & $\geq 0.94$ \\
\hline Efficiency & $\geq 0.84$ \\
\hline Cooling & Forced \\
\hline Ingress protection rating & up to $40^{\circ} \mathrm{C}$ \\
\hline Ambient temperature
\end{tabular}

Motor car is equipped with four motors: two in the front bogie (M1 and M2) and two in the rear bogie (M3 and M4). Two motors are supplied from a common inverter - see Fig.2. Each motor, via a mechanical gearbox, drives one bogie axle, to which the drive wheels are attached. Motors common to one bogie drive two different axles; these axles are connected via the drive wheels and rails. Therefore, this drive system may be classified as parallel operation of two motors supplied from a common inverter and driving a common system of mechanical axles. Motor pairs M1 and M2, M3 and M4, if mounted casually, may differ in parameters within the allowable tolerance range set out in standard [3].

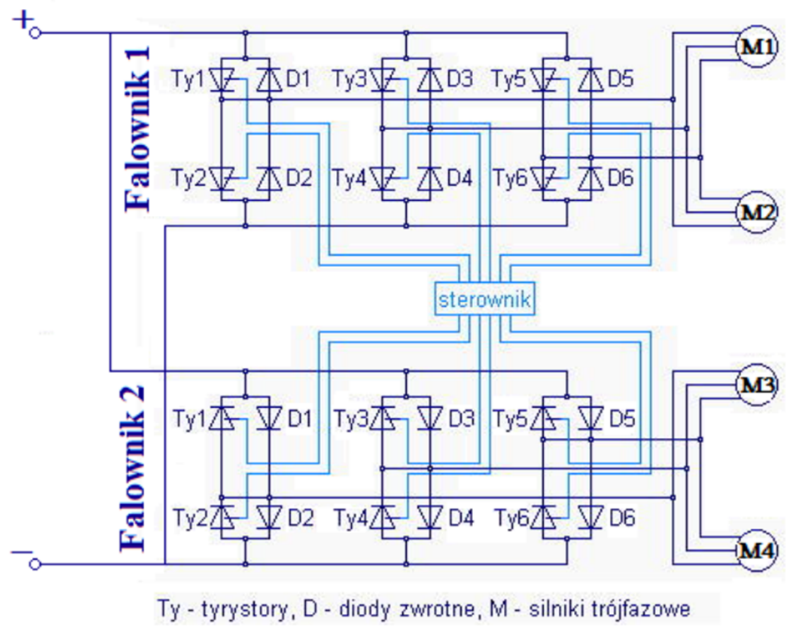

Fig. 2. Electrical scheme of LK-450 X6 motor supply - motor car.

Examples of current RMS-value waveform of M1 and M2 currents are shown in Fig.3. Differences in instantaneous values of RMS current are as high as 100\%; this proves that motors have not been selected (matched) properly. When train is braked (Fig.4), the differences in motor loadings are even greater.

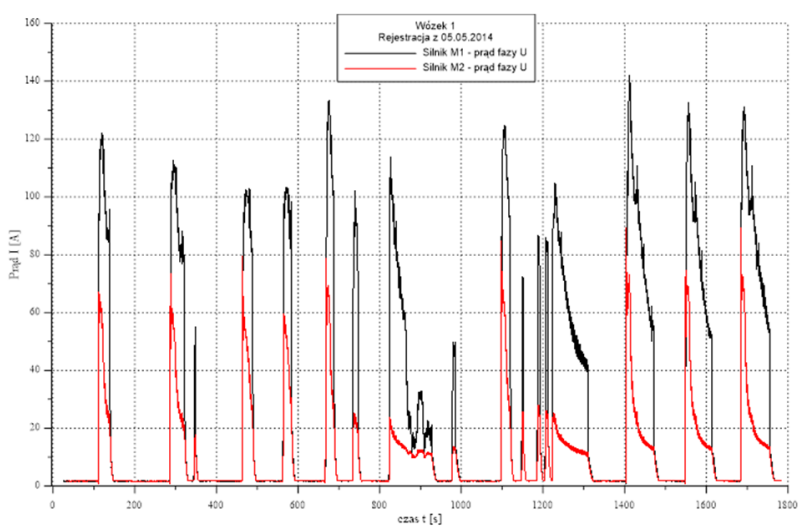

Fig. 3. Waveforms of currents (RMS values), motors M1 and M2, during train run.

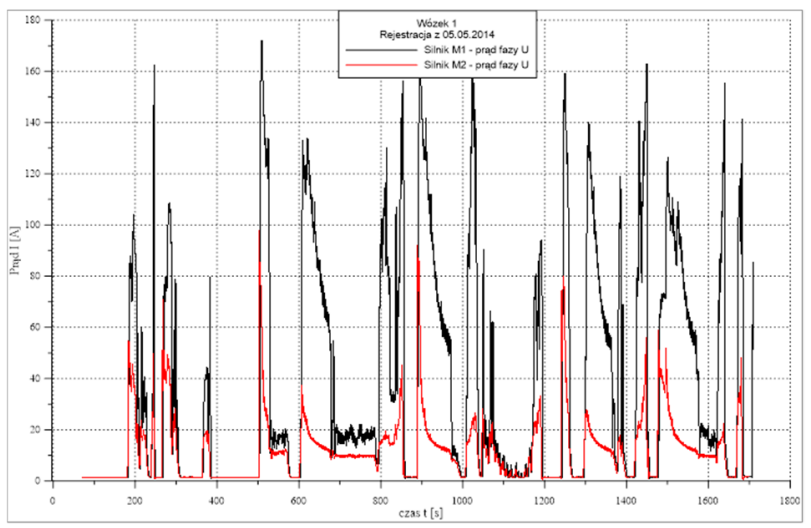

Fig. 4. Waveforms of currents (RMS values), motors M1 and M2, during train braking with braking energy recuperated. 
Figs. 5 and 6 show similar waveforms for motors M3 and M4 of bogie \#2. The differences in motor loading are much smaller. The motors for parallel operation must be selected (matched) in such a way, that their parameters should be nearly the same. If motors are properly matched, then difference in load currents should not exceed $10 \%$.

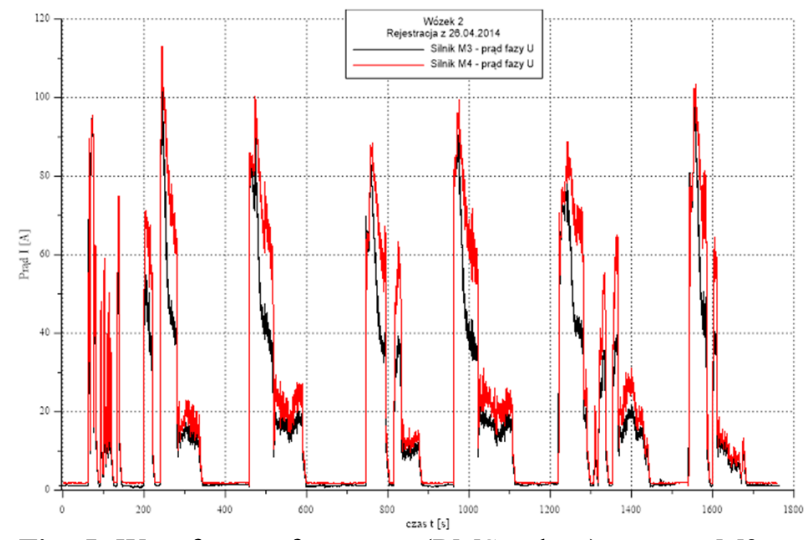

Fig. 5. Waveforms of currents (RMS values), motors M3 and M4, during train run.

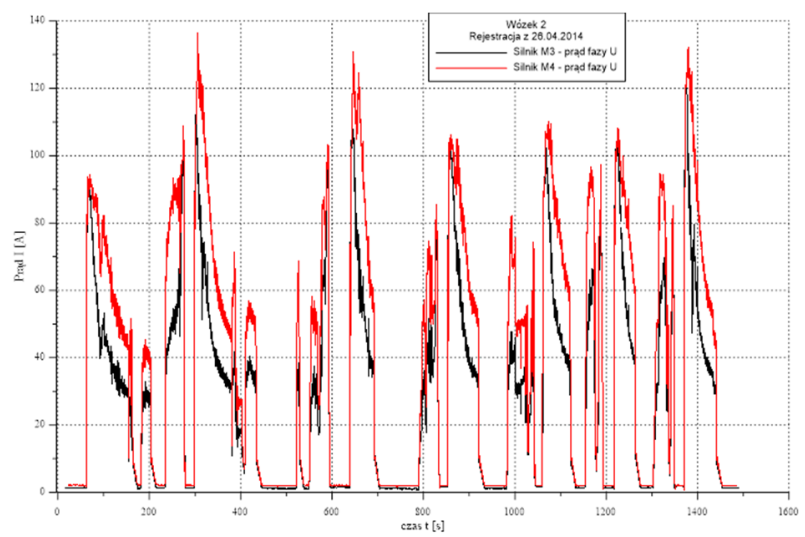

Fig. 6. Waveforms of currents (RMS values), motors M3 and M4, during train braking with braking energy recuperated.

Proper selection of motors may be achieved by using:

- no-load curves $I_{0}=\mathrm{f}(U)$ or simply $I_{0}$ at $U_{\mathrm{N}}$ and

- short-circuit curve $U_{\mathrm{z}}=\mathrm{f}(I)$ or just $u_{\mathrm{Z}}$ at $I_{\mathrm{N}}$.

The curves or parameters $I_{0}$ and $u_{\mathrm{z}}$ are measured by the manufacturer during product tests and are set out in the motor machine card; they are known to the service teams assembling motors into bogies.

Vibrations transmitted to motors by the bogie constitute another problem. Motors are attached to the bogie frame and mounted (by axial slide bearing) to the drive wheels' axles; this results in transmitting wheel vibrations to the motor. Standard PN-EN 61373 (IEC61373) specifies requirements as to tests of railway vehicle equipment subjected to vibrations and shocks, arising from the peculiarities of railway operation environment [4]. Maximum RMS-values for vibration accelerations, in accordance with Appendix A.3 of the Standard (category 3 - equipment mounted at wheelset axle), are equal to:

- vertical axis $43 \mathrm{~m} / \mathrm{s} 2$ (c. $4.3 \mathrm{~g})$;

- lateral axis $39 \mathrm{~m} / \mathrm{s} 2$ (c. $3.9 \mathrm{~g})$;
- longitudinal axis $20 \mathrm{~m} / \mathrm{s} 2$ (c. $2.0 \mathrm{~g}$ ).

According to these requirements, the LK450 X6 motor during operation may be subjected to vibrations with maximum acceleration equal to $43 \mathrm{~m} / \mathrm{s}^{2}$ (c. $4.3 \mathrm{~g}$ ). LK 450 X6 motor was tested by the manufacturer (complete tests), with vibrations equalling $50 \mathrm{~m} / \mathrm{s}^{2}$ (directions $\mathrm{x}, \mathrm{y}, \mathrm{z}$ ) and test results were positive.

Vibration acceleration measurements of LK-450 X6 motor were carried out during train run. Example of vibration acceleration waveform is given in Fig.7. The tests show that motors during normal operation were subjected to vibration accelerations as high as $150 \mathrm{~m} / \mathrm{s}^{2}$.

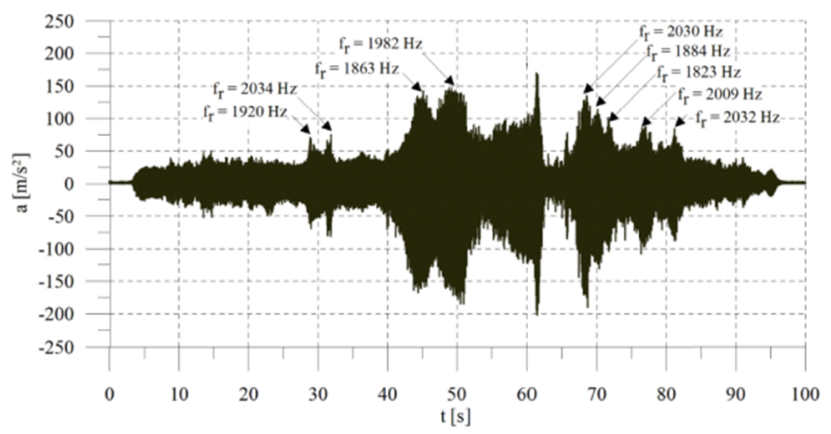

Fig. 7. LK-450 X6 motor vibration acceleration waveform, recorded on 23.04.2014.

LK-450 X6 motors fulfil the standard requirements [4]; however, vibrations acting upon the motors during normal operation attain values three times as high as values set out in the standard.

The third factor adversely influencing motor durability is backlash in the mechanical gear. Transmission of driving torque from motor shaft to bogie drive axle is achieved via mechanical gear. Small toothed gear (pinion) is mounted in the motor shaft, while main gear is attached rigidly to the car drive axle. Toothed gear is characterized by backlash. Induction motor supplied from inverter generates variable components of electromagnetic torque, apart from the constant component. This is a natural effect. These variable components of electromagnetic torque, when load at shaft is small and constant component of electromagnetic torque is likewise low, may result in appearance of negative instantaneous values of total electromagnetic torque. In the backlash range the motor's rotor will accelerate and decelerate. The main gear (which is rigidly fixed to the drive wheels' axle), will tend to maintain a constant rotational speed, on account of high car inertia. The backlash between gear teeth will produce clatter and mutual abrasion of gear teeth, which in turn will enlarge the backlash. When rotor accelerates and gear teeth come into contact, a sudden (surge) deceleration and braking of rotor will take place. A derivative of rotor' angular speed generates dynamic torque, which acts upon constructional elements of the rotor, including end-rings short-circuiting rotor bars. Shearing torque affecting the junction between bars and ring is equal to $J_{\mathrm{p}}\left(\mathrm{d} \omega_{\mathrm{m}} / \mathrm{dt}\right)$, where $J_{\mathrm{p}}$ is moment of inertia of the end-ring, and $\omega_{\mathrm{m}}$ is rotor's angular speed. This torque causes fatigue cracking of junction between rings and winding bars. The backlash (clearance) should be eliminated from torque transmission path, and toothed 
gear and the motor should be elastically unsprung from the drive wheels and entire car mass.

\section{Innovative design of rotor winding}

Innovative design of rotor winding is shown in Figs. 8-12 [1]. Fig. 8 demonstrates the longitudinal cross-section of the rotor, lower and upper layer winding bars are shown in Figs. 9 and 10, respectively, the end-rings with tongues are given in Fig. 11 and junction of winding to the endring is illustrated in Fig. 12.

Rotor winding of traction induction motor is twolayered. Turns are insulated and winding is fixed in the slot part with wedges, and coil outhangs are protected with special cloth ("bandages"). Winding bars in the lower winding layer (2.2), in the outhang part near the laminations (1), are radially bent towards shaft axis (8) and are circumferentially formed as shown in Fig.9. Specially formed outhangs of the lower layer bars (2.2) are placed on coil supports (6), which in turn are fixed to rotor laminations (1), or lie upon the shaft (8). Inner protective cloth ("bandage") (3.2) is wound around outhangs of the lower layer winding (2.2). All bar ends of the upper layer winding (2.1) and lower layer winding (2.2) are connected by ferrules at both sides of rotor laminations (1). Coil outhangs of the upper layer winding (2.1) are covered with outer protective cloth ("bandage") (3.1). A ring (5) (copper if possible) is placed either at shaft (8) or at coil support (6), on one side relative to laminations. This ring is distinguished by uniformly spaced tongues (5.1), $\mathrm{mp}$ in number ( $\mathrm{p}$ is number of winding pair poles; $\mathrm{m}$ is equal to number of rotor winding phases). Tongues (5.1) are connected with the ferrules, which are also uniformly distant one from the other along the circumference. The ring (5) may be insulated from the shaft (8) by insulation sleeve (7); however, it may be also placed directly upon the shaft (8). It is beneficial to attach the ring (5) to the lateral surface of coil support (6), instead of placing it upon the shaft, since in such case the tongues (5.1) joining ring (5) to ferrules may be shorter. The easiest way of attaching end-ring (5) to the coil support (6) is by using screws. The tongues (5.1) may be formed by e.g. casting (together with the ring); they may also be welded (or thermally welded) or soldered to ring (5). Number of rotor slots should fulfil the condition that quotient $\mathrm{Q} / \mathrm{mp}$ is an integer number ( $\mathrm{Q}$ is number of slots). Winding with number of pole pairs $\mathrm{p}=2$ and 36 slots is shown in Fig.12. The ferrules connecting the upper bars (2.1) to lower bars (2.2) produce a closed ring out of winding. Connecting any $\mathrm{mp}$ ferrules (symmetrically placed along the circumference) to the end-ring (5), provided that $\mathrm{m}=3$, generates a 3 -phase winding with delta arrangement, with number of parallel groups equal to p. Ring (5) short-circuits the winding. The coil outhangs are covered with two layers of protective clothing: outer (3.1) and inner (3.2) "bandages". The cloths (3.1) and (3.2) are best manufactured from carbon fibre tape such as NEOXECOVER or glass fibre tape or composite tape (plastic material strengthened with fibre). Bending of coil outhangs (2.2) of the lower winding layer towards the shaft axis (8) creates space for the inner "bandage" (3.2), which protects the coil outhangs from deformation due to centrifugal forces.

Traction induction motor with rotor manufactured in accordance with above described design does not possess end rings; hence, the reason for high failure rates of induction traction motor is eliminated.

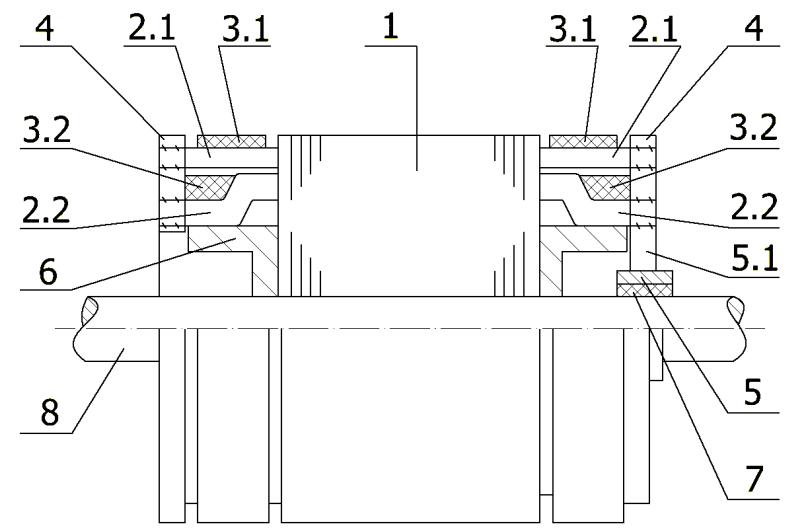

Fig. 8. Longitudinal cross-section of rotor.

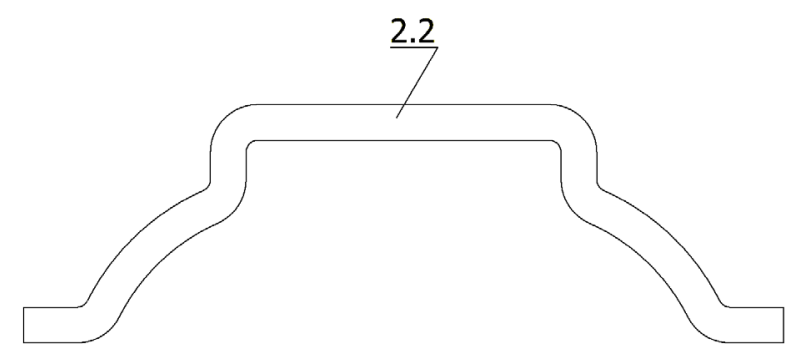

Fig. 9. Bar of winding's lower layer.

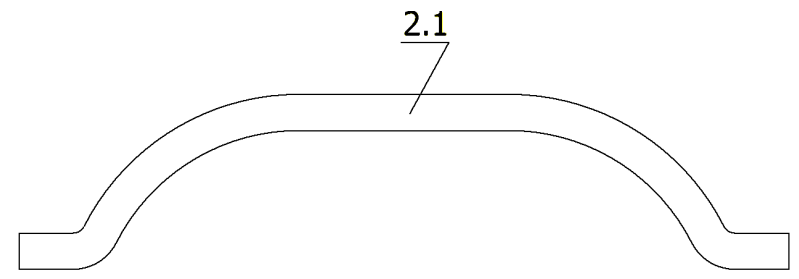

Fig. 10. Bar of winding's upper layer.

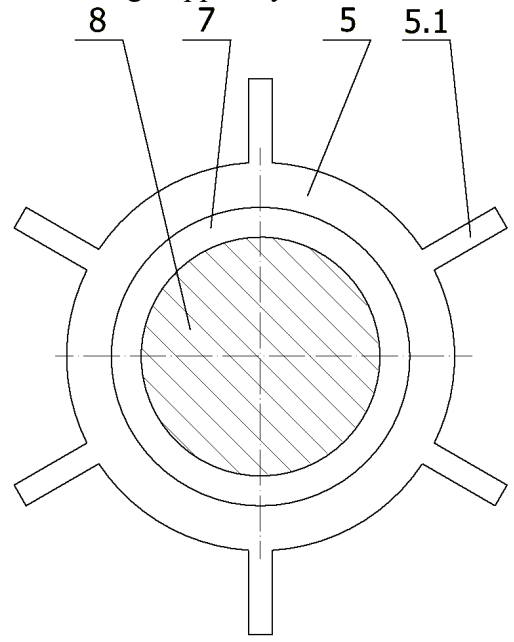

Fig. 11. End-ring with tongues. 


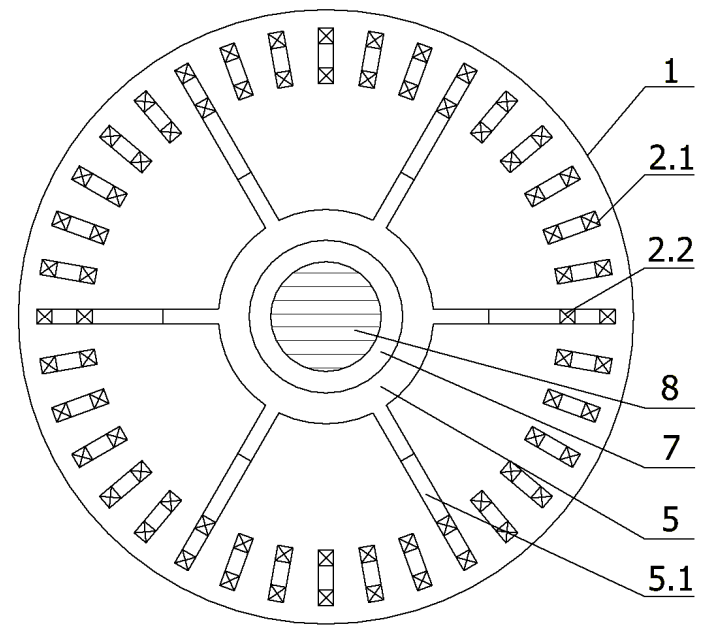

Fig. 12. Connection of winding to end-ring.

\section{Conclusions}

Replacing dc drive systems present in EMUs EN57 with asynchronous drives lowers energy consumption by several per cent, which is beneficial. The unfavourable effect is high failure rate of utilized LK-450 X6 induction motors. The rotor winding is often damaged due to cracking in end-rings which short circuit winding bars. Observation and testing of motor currents and vibrations in running trains has made it possible to ascertain reasons of this phenomenon. These are:

- non-uniform loading of motors supplied from one inverter, this is caused by improper selection (matching) of motors,
- vibrations transmitted to motor from bogie,

- backlash in mechanical gear.

We have proposed innovative design of rotor winding. The winding is $\mathrm{m}$-phase, best if it is three-phase and connected into delta arrangement. The winding ends are short-circuited with the ring attached either to coil support or mounted directly on the motor shaft.

\section{References}

1. J. Bernatt, S. Gawron, T. Glinka, W. Poprawski, Uzwojenie wirnika silnika indukcyjnego trakcyjnego (Rotor winding of traction induction motor - in Polish), Patent application P.418971, 03.01.2016.

2. R.N. Lal Ganesh, Development of reliable designs of squirrel cage rotors for traction motors used in locomotives working in ardnous operating conditions, IET Electric Power Applications, vol 4, 487-499 (2010)

3. Polish Standard PN-EN 60349-2 (IEC 60349-2), Trakcja Elektryczna - Maszyny pradu przemiennego zasilane z przeksztaltników elektronicznych (Electric traction - Rotating electrical machines for rail and road vehicles, (2011)

4. Polish Standard PN-EN 61373 (IEC 61373), Zastosowania kolejowe. Wyposażenie taboru kolejowego. Badanie odporności na udary mechaniczne $i$ wibracje (Railway applications Rolling stock equipment - Shock and vibration tests), (2011) 